\title{
Low Temperature Catalytic-Transfer Hydrogenation of Candlenut Oil
}

\author{
Fitri Hadiah", Tatang Hernas Soerawidjaja*, Subagjo ${ }^{*}$, Tirto Prakoso*

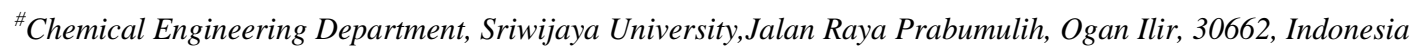 \\ E-mail: giftri@yahoo.com
}

${ }^{*}$ Chemical Engineering Department, Institute Technology of Bandung, Jalan Ganesha 10,Bandung, 40132, Indonesia
E-mail: tatanghs@che.itb.ac.id, subagjo@che.itb.ac.id, tirto@che.itb.ac.id

\begin{abstract}
Fatty acids containing more than one double bond (polyunsaturated fatty acids) indicated by high iodine value (more than $120 \mathrm{~g} \mathrm{I}_{2} / 100 \mathrm{~g}$ oil) are prone either to oxidative degradation or thermal degradation leading to the appearance of undesirable compounds or to thermal oligo-/polymerization causing gum formation. Therefore, polyunsaturated bonds in the fatty acid chains should be hydrogenated into monounsaturated ones. The conventional method using hydrogen (direct hydrogenation) at relatively high temperature and pressure with the aid of nickel as a catalyst, which prone to explosion due to the presence of free gaseous hydrogen at high temperature and pressure. Catalytic transfer-hydrogenation (CTH) therefore is proposed as a promising alternative method, enabling CTH at room condition without the presence of free hydrogen. This research is focused on exploring effects of temperature and reaction time to iodine value reduction on CTH of candlenut oil, including the kinetics of its methyl ester. The hydrogenation utilizes Ag-Ni/silica $150 \AA$ as catalyst and potassium formate (6M) as hydrogen donor. Three reaction temperatures were selected $\left(40^{\circ} \mathrm{C}, 60^{\circ} \mathrm{C}\right.$, and $\left.78^{\circ} \mathrm{C}\right)$, where each reaction was performed for $4,8,12$ and 16 hours. Hydrogenation was performed in a batch reactor using isopropyl alcohol as a solvent. Results showed that iodine values decreased with the increase of temperature and longer reaction time. The iodine value was still decreasing at $\mathbf{1 6}$ hours reaction time, indicating the possibility of longer reaction time. However, at 16 hours time, the iodine value yield has been within standard biodiesel range (Indonesian National Standard). The hydrogenation was first order reaction towards methyl ester double bonds concentration. $K_{0}$ and $E$ for candlenut methyl ester were $163.15 /$ hour and $25.26 \mathrm{~kJ} / \mathrm{mol}$.
\end{abstract}

Keywords - catalytic-transfer hydrogenation; iodine value; Ag-Ni/silica; candlenut oil; polyunsaturated fatty acid

\section{INTRODUCTION}

Biodiesel is a renewable, clean-burning diesel replacement that would reduce Indonesia's dependence on imported diesel. This fuel also has a contribution to creating green jobs and improving our environment. Candlenut oil is one of a potential alternative raw material for biodiesel production in Indonesia. Candlenut tree can produce $30-80 \mathrm{~kg}$ of nuts, yielding 60 to $66 \%$ oil (\% weight). Candlenut oil (CNO) contains palmitic acid (4-9\%), stearic acid (4-7\%), oleic acid (10-35\%), linoleic acid (33-485) and linolenic acid (23-35\%) [1], with iodine value about 136-167 $\mathrm{g} \mathrm{I}_{2} / 100$-g oil. Fig. 1 shows candlenut fruits and nuts.

However, problems associated with the use of $1^{\text {st }}$ generation biodiesel remain its oxidative susceptibility to ambient air oxygen, its low-temperature performance and its higher $\mathrm{NO}_{\mathrm{x}}$ emissions [2]. Linoleic and linolenic acids that contain more than one double bonds (polyunsaturated fatty acid) make them susceptible either to oxidative degradation leading to the appearance of undesirable compounds or to thermal oligo-/polymerization causing gum formation.
Besides that, exposure of mild steel in biodiesel can increase its oxidation instability. This is further increased due to increasing of immersion temperature [3]. For the sake of utilization of fatty oils in liquid fuel production, the polyunsaturated bonds in the fatty acid chains should be converted into monounsaturated ones.

The conventional method of doing this is by direct catalytic hydrogenation using hydrogen at relatively high temperature and pressure with the aid of nickel as catalyst. This conventional process has high explosion risk due to the presence of free gaseous hydrogen at high temperature and pressure. Another disadvantage of direct hydrogenation using nickel is that the catalyst would generate undesirable trans unsaturated chain from the cis-unsaturated chain if the hydrogenation is performed at a temperature higher than $100^{\circ} \mathrm{C}$ [4]. Unsaturated trans fatty acid is known for its higher freezing point compared to the unsaturated cis-fatty acid [5], making it not suitable for fuel component that require a lower freezing point. To overcome the risk, catalytic transfer hydrogenation $(\mathrm{CTH})$ is proposed. 


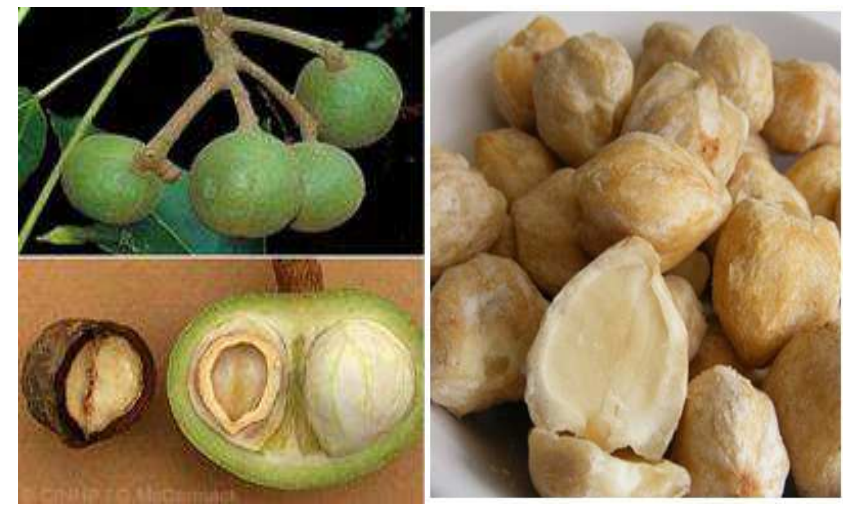

Fig. 1 Candlenut fruits and nuts

$\mathrm{CTH}$ reaction, referring to the addition of hydrogen to a molecule from a non- $\mathrm{H}_{2}$ hydrogen gas source, is a convenient and powerful method to access various hydrogenated compounds. It is an attractive alternative to direct hydrogenation, and it has recently become the centre of research in hydrogenation science. The reasons for that are (i) the CTH method does not require eventually hazardous pressurized $\mathrm{H}_{2}$ gas nor elaborate experimental setups, (ii) the hydrogen donors are readily available, inexpensive, and easy to handle, (iii) the major side product can be recycled, and (iv) the catalysts that are involved usually are readily accessible and not sensitive [6].

Catalyst selection for hydrogenation depends on the type of metal, support, solvent, temperature, the presence of poison, and the promoter. Catalyst would be selected if it has following characteristics [7]:

- the catalyst must be separable from the oil without particular difficulty;

- it must offer abundant, easily accessible surface to triglyceride molecules for contact with hydrogen adsorbed there and easy departure afterward from the surface into the main bulk of the oil;

- the catalyst is neither too sensitive to chemical attack (poisoning) nor mechanical degradation; this will be advantageous since this twofold durability permits repeated use, and hence, greater economy.

Usually, hydrogenation utilizes palladium (Pd), platinum $(\mathrm{Pt})$, ruthenium $(\mathrm{Ru})$, rhodium $(\mathrm{Rh})$, iridium $(\mathrm{Ir})$, copper $(\mathrm{Cu})$ and nickel $(\mathrm{Ni})$ as catalysts. Although nickel is the least expensive, palladium has been preferred for CTH, because of its higher efficiency and its selectivity with respect to reaction products [8]. The order of catalyst activity is $\mathrm{Pd}>\mathrm{Rh}>\mathrm{Pt}>\mathrm{Ru}>\mathrm{Ni}>\mathrm{Cu}$. High catalyst activity (15-100 times compared to nickel) and does not need high temperature and pressure are the other reasons why palladium is preferred as a hydrogenation catalyst. Various palladium based catalyst have been used, such as $\mathrm{Pd} / \mathrm{C} 10 \%$ [9], [10], $\mathrm{Pd} / \mathrm{C} 1 \%$ [11], $\mathrm{Pd} / \mathrm{C} 0.2-0.4 \%$ [11], Pd/C $0.5-2 \%$ [12] , $\mathrm{Pd}-\mathrm{Zr}_{2} \mathrm{O}, \mathrm{Pd}-\mathrm{Ti}_{2} \mathrm{O}$ and $\mathrm{Pd}-\mathrm{Al}_{2} \mathrm{O}_{3}$ [13]. However, palladium could increase trans fatty acids formation. The order of trans-fatty acid formation is $\mathrm{Pd}>\mathrm{Rh}>\mathrm{Ru}>\mathrm{Pt}$ ). Hence, platinum also preferred as hydrogenation catalyst, such asPt- $\mathrm{Zr}_{2} \mathrm{O}, \mathrm{Pt}_{-} \mathrm{Ti}_{2} \mathrm{O}$ and Pt$\mathrm{Al}_{2} \mathrm{O}_{3}$ [12] and $\mathrm{Pt} / \mathrm{C} 5 \%$ [14], [15]. The other noble metals used as hydrogenation catalyst were ruthenium $(\mathrm{Ru} / \mathrm{C}[15]$,
[16], $\mathrm{Ru} / \mathrm{MgO}[16]$ and rhodium [rhodium triphenilphosphite sulphonat [17].

Other catalysts that used in catalytic hydrogenation and/or catalytic transfer-hydrogenation were copper (II) dichromate [18],copper (II) carbonate [19], Ni/silica $0.012-0.039 \%$ [20], Ni comercial [21], [22]. Copper and nickel based catalyst required high temperature $\left(120-200^{\circ} \mathrm{C}\right)$ to be fully functional.

Nickel (Ni) as a catalyst has some advantages, such as high activity, selective to linolenic acid, and relatively affordable. Nickel could be easily separated using filtration too. Unfortunately, nickel needs high temperature and pressure to activate so it would lead to higher isomerization rate of cis-fatty acid towards trans-fatty acid. Hence, it needs further research to minimize the formation of trans fatty acid yet enhancing the activity of nickel as a catalyst at lower or slightly above ambient temperature.

Bimetallic catalysts using $\mathrm{Ni}$ and noble metals have been researched, such as Ni-Ag [24], [25], [26], Ni-Pd [26], Ni$\mathrm{Cu}$ [27], Ra-Ni [14], Ni-Mg [13], [28]. Noble metals that have potential to develop are silver because the price is more affordable than palladium and platinum based catalysts. The bimetallic catalyst in the form of $\mathrm{Ag}-\mathrm{Ni} / \mathrm{silica}$ made by precipitation method proved to be effectively reducing benzene up to $100 \%$ conversion at $100^{\circ} \mathrm{C}$ [25], [26]. Bimetallic catalyst $\mathrm{Ag}-\mathrm{Ni} / \mathrm{ZrO}_{2}$ has been used on catalytictransfer hydrogenation of levulinate acid with hydrogen donor from formic acid and showed good synergy of Ag and $\mathrm{Ni}$ to eliminate the need of external hydrogen requirement [26]. Bimetallic and polymetallic catalysts have a bright future in catalysis because of their enhanced activities, stabilities, selectivity, synergistic effects, and other properties as compared to their monometallic counterparts. Several bimetallic and polymetallic complexes and nanocatalysts recently appeared in CTH processes [6]. These previous research corroborate hypotheses that the bimetallic Ag-Ni can be employed as a catalytic transfer-hydrogenation catalyst of vegetable oils in appropriate operating conditions.

Hydrogen donor source could be inferred from water $\left(\mathrm{H}_{2} \mathrm{O}\right)$, organic solvents, or a combination of both sources [29]. Limonene was considered as one of promising hydrogen donors because it provided acid conversion up to $100 \%$ on hydrogenation of castor oil [8]. Meanwhile, 1:3 optimum ratio of oil/limonene was reported on hydrogenation of sunflower oil [12]. Unfortunately, limonene price is rather high and not widely available. Other hydrogen donors that have been studied are indoline, ethyl alcohol and isopropyl alcohol [30], but those reagents could only provide high partial hydrogenation selectivity on highpressure condition (>165 psig). The commonly used hydrogen donors are cyclohexane, cyclohexadiene, phosphoric acid, hydrazine, formic acid, sodium formate, ammonium formate, and sodium hypophosphate [31].

Hence, it is needed to provide a feasible hydrogen donor that could overcome those limitations with the following physical and chemical characteristics:

- Liquid for easier handling,

- Readily available and affordable

- Could be regenerated (by reduction) either by direct hydrogenation or electrochemical hydrogenation. 
One of the promising hydrogen donors that met above characteristics is formate salt. Some research on this material related to the CTH of fatty acids is on salts of natrium, potassium, or ammonium formate [10], [11], [32], [33]. Various formic acid salts were used as hydrogen donors in organic and aqueous media at CTH of soybean oil [10]. In organic media, the linoleic acid content only decreased to $13.1 \%$, and there's no increasing of stearic acid after $24 \mathrm{~h}$ of reaction time, whereas in an aqueous medium the linoleic acid content decreased to $1.4 \%$ and stearic acid increased from 5.4 to $10.8 \%$ after $33 \mathrm{~h}$ of reaction time.

High concentration of potassium formate $(10 \mathrm{M})$ can increase the rate of vegetable oils hydrogenation [10], so potassium formate was used in this research as a hydrogen donor for $\mathrm{CTH}$ because of its high solubility in water (330g/100g $\left.\mathrm{H}_{2} \mathrm{O}\right)$. Potassium formate $(\mathrm{KCOOH})$ would disproportionate into hydrogen and potassium bicarbonate in the present of the catalyst.

Solvents were utilized in CTH to boost hydrogenation process, because it might ease hydrogen and oil contacting catalyst surface as the effect of more freely diffusion [34], thus increasing hydrogen and oil adsorption capability [35]. Solvents would also make the polyunsaturated converted into monounsaturated without advancing into saturated ones and only producing few trans-fatty acids [36]. Solvents could be utilized to lower the viscosity of reaction mixture, hence easier to perform the mass transfer, increasing hydrogen solubility in fluid phase as well as the hydrogenation products' solvent [34]. So far, the best solvents for hydrogenations are water, alcohol, ether [34], [35], [36], acetone, ethyl ether [34], [37], hexane [34], denatured absolute ethanol (95\%-v ethanol - 5\%-v methanol), methanol, isopropyl alcohol, cyclohexanol [37].

\section{MATERIAL AND METHOD}

\section{A. Material}

Candlenut oil (CNO) with an acid value about $10 \mathrm{mg}$ $\mathrm{KOH} / \mathrm{g}$ (pressed in our own laboratory) and iodine value160.98 $\mathrm{g} \mathrm{I}_{2} / 100 \mathrm{~g}$ oil was used, mixed with isopropyl alcohol, potassium carbonate technical grade (Bratachem), and formic acid (Merck).

\section{B. Catalyst Preparation}

Silica gel Davisil grade (average pore diameter $150 \AA$ A) was wetted with potassium formate that dissolved in distilled water. Catalyst candidate was dried at room temperature for 12 hours. Meanwhile, $\mathrm{Ni}\left(\mathrm{NO}_{3}\right)_{2} \cdot 6 \mathrm{H}_{2} \mathrm{O}$ and $\mathrm{AgNO}_{3}$ were dissolved in distilled water. Catalyst candidate and nitrate solution were stored in the freezer for 12 hours. The catalyst candidate was then wetted with nitrate solution and dried at room temperature. Catalyst candidate then filtered on cold Buchner funnel and washed 5 times with cold distilled water. The catalyst was dried first at room temperature and then in a vacuum oven at $75^{\circ} \mathrm{C}$ until it turned black.

\section{Transesterification of Candlenut Oil}

Candlenut oils were deacidified first according to deacidification method proposed by [38]. Transesterification was performed using 100 grams of candlenut oil (acid value $<1 \mathrm{mg} \mathrm{KOH} / \mathrm{g}$ ) mixed with 25-gram acetone, $20 \mathrm{ml}$ of methanol, and 5 milliliters of potassium methoxide (30-32\%).
This transesterification was performed in 1 hour and deactivated by addition of phosphoric acid $85 \%(0.5 \mathrm{ml})$. Methyl ester then separated from glycerol, washed with distilled water, and dried in desiccators.

\section{Hydrogenation Donor ( $\mathrm{KCOOH}$ ) Preparation}

Based on potassium formate production method [39] Potassium carbonate (248.5 grams) was dissolved in 1 liter distilled water and stirred gently. Formic acid (136.5 ml) was added slowly. After the $\mathrm{CO}_{2}$ evolution was complete, the solution was evaporated to dryness and the solid obtained was then dried in an oven at $150^{\circ} \mathrm{C}$ for 48 hours.

\section{E. CTH Procedure}

CTH of candlenut methyl ester utilized Ag-Ni/silica $150 \AA$ $4 \%-\mathrm{w}$ as catalyst and $6 \mathrm{M}$ potassium formate $(\mathrm{KOOCH})$ solutions as hydrogen donor. The CTH was performed in a batch reactor (Fig. 2 show reactor configuration) and atmospheric pressure. Isopropyl alcohol was used as solvent with ratio 5:1 to fatty oil. At the end of the $16 \mathrm{hrs}$ reaction time, hydrogenated fatty oil was separated from the Isopropyl alcohol and $\mathrm{KCOOH} / \mathrm{KHCO}_{3}$. It was then washed with distilled water to remove traces of $\mathrm{KCOOH} / \mathrm{KHCO}_{3}$ until the $\mathrm{pH}$ of wash water was neutral. The iodine value of the fatty oils was measured using Wijs method (FBI-A0403).

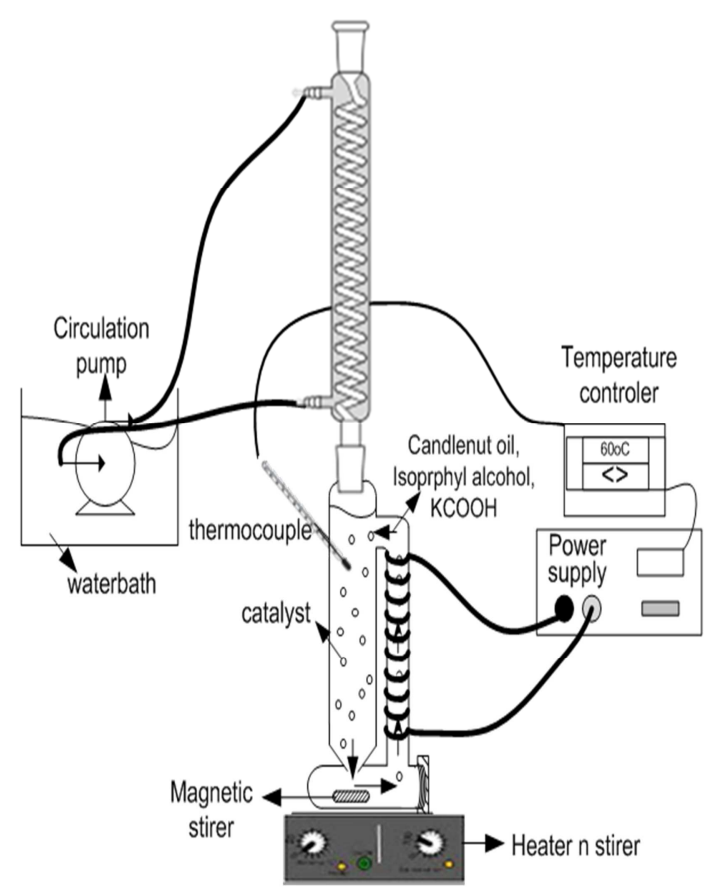

Fig. 2 Reactor configuration

\section{RESULT AND DISCUSSION}

\section{A. Catalyst Characteristic}

The catalyst was made by previously impregnating potassium formate, into silica $150 \AA$ Davisil grade in order to make better adsorption since silica was acid based while potassium formate is naturally base. Silica was selected because it has some advantage, such as affordable, easy to use, and easy to separate, has high thermal and mechanical 
stability, and has high surface area and porous volume. Nitrate salts were impregnated at a temperature below $15^{\circ} \mathrm{C}$, so silver will not reduce nickel nitrate first before nickel nitrate reacts with formate ion. Impregnated nitrate salts (nickel nitrate and silver nitrate) then reacted to potassium formate forming nickel formate, silver formate, and potassium nitrate. Nickel formate and silver formate are easier to settle on catalysts surface because their solubility in water is lower than potassium nitrate. The solubility of potassium nitrate in water is $33 \mathrm{~g} / 100 \mathrm{~g}$, nickel formate is $3,25 \mathrm{~g} / 100 \mathrm{~g}$, while silver formate is not soluble in water. This condition is advantageous especially on catalysts washing because only potassium nitrates that soluble into washing water.

The BET surface area of $\mathrm{Ag}-\mathrm{Ni} / \mathrm{SiO}_{2}$ catalyst was $283.47 \mathrm{~m}^{2} / \mathrm{g}$, and the average pore size was $137.36 \AA$. Thus, very large average pore size increasing the adsorption rate of the unsaturated fatty acid, which has molecule size around $25 \AA$ A According to XRF (X-Ray Fluorescence analysis), the $\mathrm{Ag}-\mathrm{Ni} / \mathrm{SiO}_{2}$ catalyst consists $3.022 \%-\mathrm{w} \mathrm{Ni}$ and $4.027 \%-\mathrm{w}$ $\mathrm{Ag}$. The composition of catalyst was analyzed qualitatively using X-Ray diffractor (XRD) as shown in Fig. 3, indicating that silver and nickel were not in oxide form, but as elements.

This finding suggests successful catalytic as elements. This finding suggests successful catalytic forming using $\mathrm{KCOOH}$. Ag-Ni/silica catalysts made through simultaneous deposition and decomposition of silver formate and nickel formate yielding $\mathrm{Ag}^{0}$ and $\mathrm{Ni}^{0}$ on the surface of silica support. This achievement is considered as a new finding, since previously, [23], [24] were using hydrazine, not potassium formate.

Nickel ions are easily reduced because the $\mathrm{Ag}^{0}$ metal particles formed to act as active centers for nickel reduction.
It has been shown that silver ions added to the reactant mixture accelerate the reduction of transition metal ions [23]. Therefore, side by side location of $\mathrm{Ni}$ and $\mathrm{Ag}$ would make the decomposition of formate ion (nickel reduction) easier. Monometallic nickel, on the other hand, is not reduced by the hydrazine but forms a $\mathrm{Ni}^{2+}$ blue complex [23]. The addition of $\mathrm{Ag}$ ions into reactant is proven to accelerate the reduction of some transition metals [39]. This phenomenon was also visible during nickel oxide reduction, by hydrogen, in the presence of $\mathrm{Ag}_{2} \mathrm{O}$ [41], [42].

Previous research about silver formate showed that as palladium formate, $\mathrm{AgOOCH}$ is unstable at room temperature and decompose autocatalytically (catalyzed by the silver from decomposition). Even, the catalyst could explode when heated in a closed room until $95^{\circ} \mathrm{C}$ [43]. Silver was also the catalyst for formic acid decomposition [44].

\section{B. Effect of Temperature and Reaction Time}

Effect of temperature and reaction time towards iodine value is shown in Fig. 4. It showed that increasing temperature and reaction time would yield lower iodine value. The expected iodine value ( $\leq 110 \mathrm{~g} \mathrm{I}_{2} / \mathrm{g}$ methyl ester) only achieved at $78^{\circ} \mathrm{C}$ and 16 hours. However, the iodine value trend showed that it still decreasing if the temperature and the reaction time extended. Thus, the expected iodine value could be achieved in shorter reaction time if the temperature is higher than $78^{\circ} \mathrm{C}$ or in longer time if the temperature is lower than $78^{\circ} \mathrm{C}$. The maximum temperature for this system is $78^{\circ} \mathrm{C}$ because the mixture of isopropyl alcohol, candlenut oil, and $\mathrm{KCOOH}$ has azeotrope at this temperature.

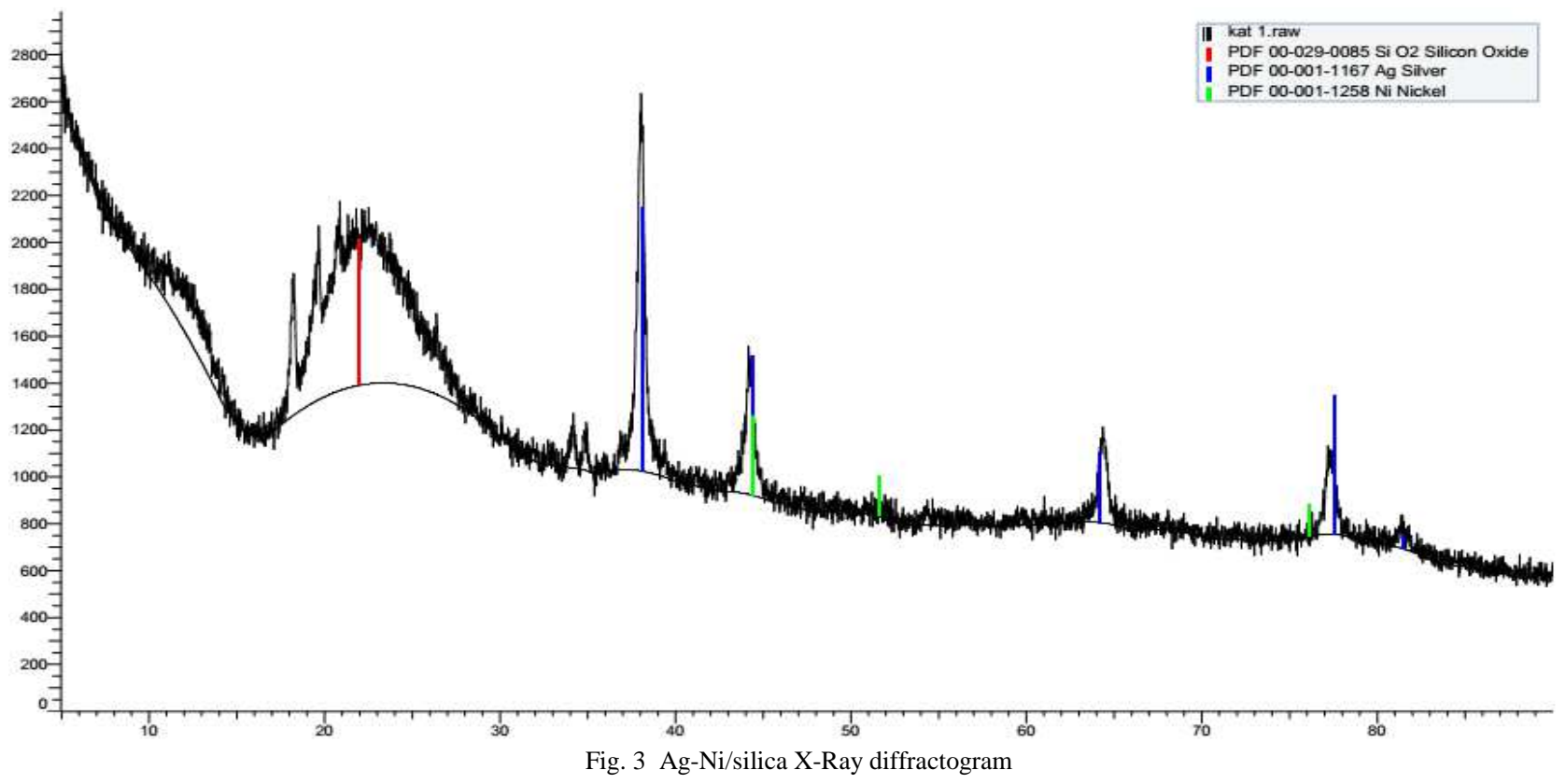




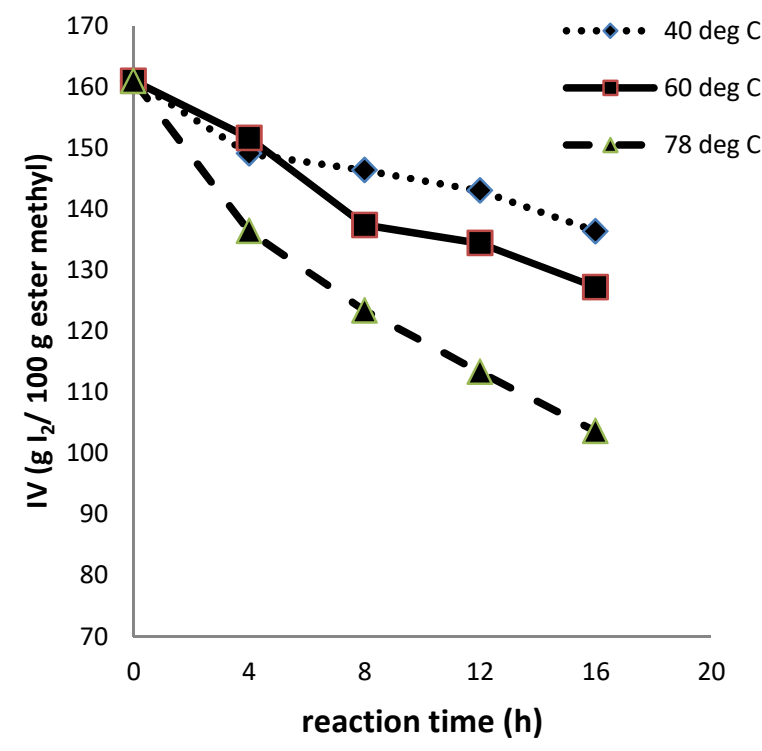

Fig. 4 Iodine value (IV) of candlenut methyl ester

Potassium formate was decomposed into hydrogen and potassium bicarbonate in the silver side, then hydrogen adsorbed in nickel side. After that, adsorbed hydrogen reacted with a double bond in nickel site. It could be concluded that silver acted as decomposition catalyst, while nickel acted as a hydrogenation catalyst. During hydrogenation, hydrogen was detected in gas output. This indicated that not all of the hydrogen was absorbed and reacted with a double bond. Higher nickel composition in the catalyst $(\geq 4 \%-\mathrm{w})$ could possibly increase adsorption and reaction rate.

\section{Hydrogenation Rate}

Hydrogenation rate was calculated according to equation 1 [43] and presented on Fig. 5.

$$
\text { Hydrogenation rate }=\frac{\left(I V_{\text {before }}-I V_{\text {after }}\right)}{I V_{\text {before }}} \times 100 \%
$$

Bimetallic Ag-Ni performed actively as hydrogenation catalyst seven at $40^{\circ} \mathrm{C}$, where nickel usually inactive. At this temperature, hydrogenation rate attained at $15.31 \%$, while at $78^{\circ} \mathrm{C}$, the hydrogenation rate reached $35.63 \%$.XRF analysis showed that $\mathrm{Ni}$ and $\mathrm{Ag}$ ratios in the catalyst were $3.022 \%-\mathrm{w}$ and $4.027 \%-\mathrm{w}$ respectively, equivalent to $43 \% \mathrm{Ni}: 57 \% \mathrm{Ag}$. This result is comparable to [23], which resulted in $20 \%$ conversion when hydrogenating benzene using $50 \% \mathrm{Ni}: 50 \%$ $\mathrm{Ag}$ and resulted in $80 \%$ conversion when $\mathrm{Ag}: \mathrm{Ni}$ ratios were $10 \%$ and $90 \%$ respectively. Meanwhile, hydrogenation performed in this research were performed at $\left(78^{\circ} \mathrm{C}\right)$, lower than $200^{\circ} \mathrm{C}$ that used on [23]. This difference is also affected by the different hydrogen source as a donor. Pure hydrogen was used on [23], while $\mathrm{KCOOH}$ was utilized in this research. Furthermore, hydrogenation on [23] was performed on benzene which is considered more difficult to hydrogenate than unsaturated fatty acids.

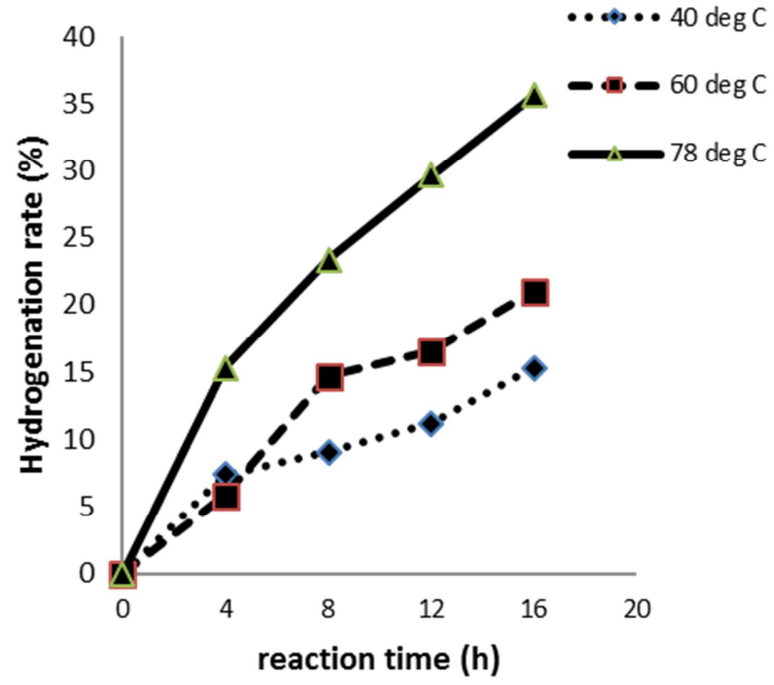

Fig. 5 Hydrogenation rate of candlenut methyl ester

\section{Catalytic-Transfer Hydrogenation}

The mechanism of the rate of reaction can be explained by the following hypothetical reactions:

$\mathrm{HCOO}^{-}+\mathrm{H}_{2} \mathrm{O}+$ Catalyst $\rightarrow$ H-Catalyst- $\mathrm{H}+\mathrm{HCO}_{3}^{-}$

$\mathrm{H}$-Catalyst-H + double bond $(\mathrm{A}) \rightarrow \mathrm{AH}_{2}+$ catalyst $\overline{\mathrm{HCOO}^{-}+\mathrm{H}_{2} \mathrm{O}+\mathrm{A} \rightarrow \mathrm{AH}_{2}+\mathrm{HCO}_{3}^{-}}$

During hydrogenation, the surface of nickel as the active catalyst would be filled by adsorbed hydrogen. Hydrogen from the $\mathrm{HCOO}^{-}$decomposition was abundant, and some were unabsorbed because the output gases from reactor contain hydrogen. Therefore, the reaction that defines the hydrogenation was the only reaction between $\mathrm{H}_{2 \text { (ads) }}$ with double bound in unsaturated fatty acid. Effect of water in solution could be neglected because the amount was also abundant. So, the reaction mechanism could be rewritten as follow:

$$
\begin{gathered}
\text { Unsaturated }(\mathrm{A}) \rightarrow \text { saturated }\left(\mathrm{AH}_{2}=\mathrm{B}\right) \\
\text { H-catalyst- } \mathrm{H}+\mathrm{A} \rightarrow \mathrm{B}+\text { cayalyst } \\
\text { H-catalyst-H } \rightarrow \text { catalyst }+\mathrm{H}_{2} \\
\frac{d A}{d t}=-\left(k_{1} \cdot \theta \mathrm{H}_{2} \cdot A\right) \\
\frac{d H_{2}}{d t}=-\left(k_{2} \cdot \theta H_{2}\right)
\end{gathered}
$$

All of the nickel surfaces were fully filled by $\mathrm{H}_{2}$, so $\Theta \mathrm{H}_{2}$ (adsorbed hydrogen fraction) was equal to 1 . Hence, the hydrogenation of the double bond (equation 5) is considered as first order reaction towards the double bond (equation 7). Meanwhile, desorption reaction of hydrogen (equation 6) is a zero order reaction.

$$
\frac{d A}{d t}=-(k \cdot A)
$$

Arrhenius equation is

$k=k_{0} e^{-E_{a} / R T}$, 
then, equation 7 become:

$$
\frac{d A}{d t}=-k_{0} e^{-E_{a} / R T A}
$$

The double bond concentration which obtained using iodine value (Fig. 3), were utilized to determined Arrhenius constant $\left(\mathrm{k}_{0}\right)$ and activated energy (E) using equation 7 . The equation was solved by Runge-Kutta and fminsearch method using Matlab R2010a. It was found that $\mathrm{k}_{\mathrm{o}}$ and $\mathrm{E}$ for candlenut methyl ester are $163.15 /$ hour and $25.26 \mathrm{~kJ} / \mathrm{mol}$. Double bond concentration during reaction time (data and model) is presented in Fig. 6.

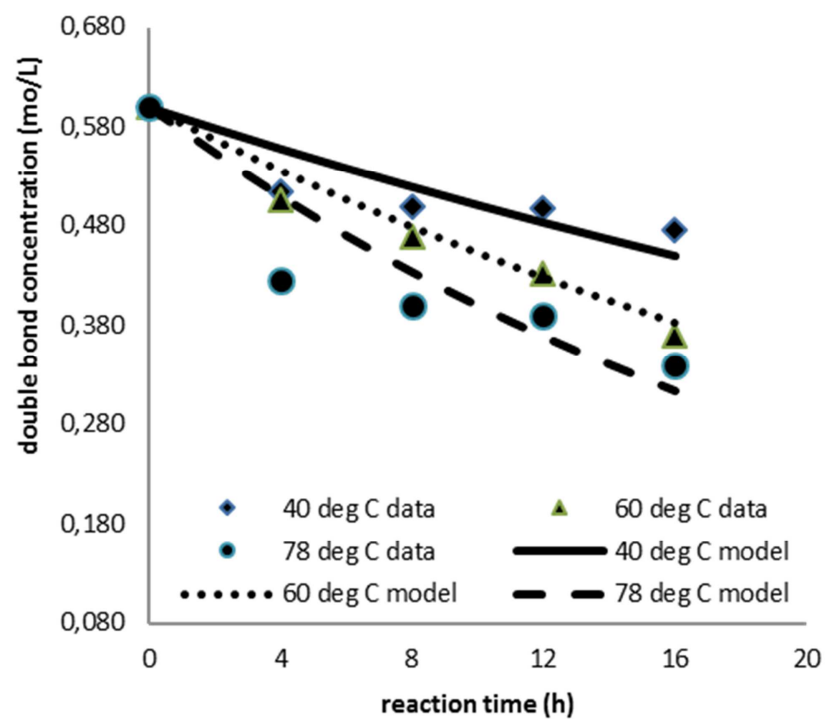

Fig. 6 Double bond concentration (data and model)

Activation energy rate produced on this research $(25.47$ $\mathrm{kJ} / \mathrm{mol}$ ) was not quite different from activation energies from catalytic transfer hydrogenation of soybean oil [34], [35], which were between $5-102 \mathrm{~kJ} / \mathrm{mol}$.Activation energy values which were lower than $40 \mathrm{~kJ} / \mathrm{mol}$ on candlenut oil hydrogenation suggests that the process rate is controlled by diffusion within the catalyst pore. But, the size of the particle was only 140-200 mesh, so this assumption is not quite reasonable.

Arrhenius constant attained in this work (2.85/minute) was positioned between the results from [43] (about 105) that approaching first-degree order reaction and [44] (about $10^{-3}$ ) that using second-degree order reaction approach. Catalysts selections, a hydrogen donor, and operation condition would affect the value of activation energy and the Arrhenius constant. Kinetic parameters on [43], [44] were evaluated from catalytic transfer hydrogenation of soybean oil at $50^{\circ} \mathrm{C}$, $65^{\circ} \mathrm{C}$ and $80^{\circ} \mathrm{C}$, which using hydrogen donor from sodium formate and palladium on carbon as catalyst.

\section{CONCLUSIONS}

The hydrogenation result showed that decreasing iodine values correspond to a higher temperature and longer reaction time. The iodine value was still decreasing at 16 hours reaction time, indicating the possibility of longer reaction time. However, at 16 hours time, the iodine value yield has been within biodiesel standard range in Indonesia. It is found that the hydrogenation is first order reaction towards methyl ester double bonds concentration. The value of $\mathrm{k}_{\mathrm{o}}$ and $\mathrm{E}$ for catalytic transfer-hydrogentaion of candlenut methyl ester are 163.15/hour and $25.26 \mathrm{~kJ} / \mathrm{mol}$.

\section{NOMENCLATURE}

A Unsaturated fatty acid

B Saturated fatty acid

E Activation energy

$\mathrm{H}_{\mathrm{ads}} \quad$ Adsorbed hydrogen

IV Iodine value

$\mathrm{k}_{0} \quad$ Arrhenius constant

$\mathrm{k}_{1} / \mathrm{k} \quad$ Hydrogenation rate constant

$\mathrm{k}_{2} \quad$ Desorption rate constant

Greek letters

$\Theta \quad$ adsorbed hydrogen fraction

Subscripts

ads adsorbed

\section{ACKNOWLEDGMENT}

The authors gratefully acknowledge the financial support from the Engineering Faculty University of Sriwijaya.

\section{REFERENCES}

[1] T.H., Soerawidjaja, Prospek dan Tantangan Pengembangan Industri Biodiesel di Indonesia, Proceeding, National Seminar Energi Hayati Sebagai Solusi Krisis Energi: Peluang dan Tantangannya di Indonesia, UNS Surakarta, 2006.

[2] A. Bouriazos, S. Sotiriou, C. Vangelis, and G.. Papadogianakis, "Catalytic conversions in green aqueous media: Part 4. Selective hydrogenation of polyunsaturated methyl esters of vegetable oils for upgrading biodiesel", Journal of Organometallic Chemistry, 2010, vol. 695 , pp. $327-337$.

[3] M. A. Fazal , A. S. M. A. Haseeb , H. H. Masjuki, "Effect of temperature on the corrosion behaviour of mild steel upon exposure to palm biodiesel", International Journal on Advance Science, Engineering, Information Technology, 2011, vol.1, no.5, pp.505-510.

[4] K. MondaL and S.B. Lalvani, "Low temperature soybean oil hydrogenation by an electrochemical process", Journal of Food Engineering, 2008, vol. 84, pp. 526-533.

[5] A.Thomas, "Fats and Fatty Oils", Ullmann Encyclopedia of Industrial Chemistry, 2005, vol. 6 no. A10, pp. 173 - 245.

[6] D. Wang, and D. Astruc, "The Golden Age of Transfer Hydrogenation", Chemical Review, 2015, vol.115, pp. 6621-6686.

[7] H.B.W. Patterson, Hydrogenation of Fats and Oils: Theory and Practise, Urbana Illinois, AOCS Press, 2009, pp.171-187.

[8] M. Martinelli, R. Scneider, V.Z Baldissarelli, M.L. Holleben, and E.B. Caramao, "Castor oil hydrogenation by a catalytic hydrogen transfer system using limonene as a hydrogen donor", Journal of American Oil Chemists Society, 2015, vol.82, pp. 279-283.

[9] M. Naglic, A. Smidnovik, and T. Koloini, "Kinetics of catalytic transfer hidrogenation of some vegetables oils", Journal of American Oil Chemists Society, 1998, vol.75, pp. 629-633.

[10] A. Smidovnik, A. Stimac, and J. Kobe, "Catalytic transfer hydrogenation of soybean", Journal of American Oil Chemists Society, 1992, vol. 69, no.5, pp. 405-409.

[11] O. Arkad, H. Wiener, N. Garti, Y. Sasson, "Catalytic transfer hydrogenation of soybean oil methyl ester using inorganic formic acid salts as donors", Journal of American Oil Chemists Society, 1987, vol. 64, pp.1529-1532.

[12] R. Schneider, L.R.S. Lara, and M. Martinelli, "An alternative process for hydrogenation of sunflower oil", Orbital The Electronis Journal of Chemistry, 2010, vol. 2 no. 2.

[13] S. McArdle, S. Girish, J.J. Leahy, and T. Curtin, "Selective hydrogenation of sunflower oil over noble catalysts", Journal of Molecular Catalysis A:Chemical, 2011, vol. 351, pp. 179-187. 
[14] K. Wan Lee, B.X. Mei, Q. Bo, Y. Wun Kim, K. Woo Chung, and Y. Han, "Catalytic selective hydrogenation of soybean oil for industrial intermediates", J.Ind.eng.Chem., 2007,vol.13 no. 4, pp. 530-536.

[15] I.V. Deliy, I.L. Simakova, N. Ravasio, and R. Psaro, "Catalytic behavior of carbon supported platinum group metals in hydrogenation and isomerization of methyl oleate", Applied Catalysis Journal, 2009, vol. 357, pp. 170-177.

[16] P.M. Arvela, J. Kuusisto, E.M. Sevilla, I. Simakova, J. Mikola, J. Myllyoja, T. Salmi, and D.Y. Murzin," Catalytic hydrogenation of linoleic acid to stearic acid over different Pd-and Ru-supported catalysts", Applied Catalysis A: General, 2008, vol. 345, pp. 201-212.

[17] N. Nikolaou, C.E. Papadopoulus, A. Lazaridou, A. Koutsoumba, A. Bouriazos, and G. Papadogianakis, "Partial hydrogenation of methyl ester of sunflower oil catalyzed by highly active rhodium sulfonate triphenylphospite complexes", Catalysis Communications, 2009, vol. 10 , pp. $451-455$

[18] H. Husin, "Katalis bimetal $\mathrm{Cu}-\mathrm{Cr}$ /diatomea untuk hidrogenasi minyak sawit", Jurnal Teknologi dan Industri Pertanian Indonesia, 2012, vol. 2, no. 4, pp. 1-6.

[19] R.T. Sleeter, "Hydrogenation with copper compositions catalys", Paten AS no. 7.491.820 B2, 2009.

[20] E.A. Cepeda, B. dan Calvo, "Sunflower oil hydrogenation: study using response surface methodology", Journal of food engineering, 2008, vol. 89 , pp. $370-374$.

[21] B. Fillion and B.I. Morsi, "Kinetics, gas-liquid mass transfer, and modelling of the soybean oil hydrogenation process", Ind. Eng. Chem. Res., 2002, vol. 41, pp. 697-709.

[22] F. Kalantari, M. Bahmaei, M. Ameri, and E. Shoeai, "Effect of vegetable oil oxidation on the hydrogenatioasn reaction process", Grasas Y Aceites, 2010, vol. 60, no.4, pp. 361-368

[23] M.M. Bettahar, R. Wojcieszak, S. Monteverdi, "NiAg catalysts prepared by reduction of $\mathrm{Ni}^{2+}$ ions in aqueous hydrazine II. Support effect", Journal of Colloid and Interface Science, 2009, vol.332, pp. 416-424.

[24] R. Wojcieszak, S. Monteverdi, J. Ghanbaja, M.M. Bettahar, "Study of $\mathrm{Ni}-\mathrm{Ag} / \mathrm{SiO}_{2}$ Catalysts Prepared by Reduction in Aqueous Hydrazine", Journal of Colloid and Interface Science, 2008, vol. 317, pp.166-174.

[25] A.M. Hengne, A.V, Malawadkar, N.S. Biradar, and C.V. Rode, "Surface synergism of an $\mathrm{Ag}-\mathrm{Ni} / \mathrm{ZrO} \mathrm{r}_{2}$ nanocomposite for the catalytic transfer hydrogenation of bio-derived platform molecules", RSC Advances, 2014, vol. 4, pp.9730-9736.

[26] A.J. Wright, A. Wong, and L.L. Diosady, "Ni catalyst promotion of a Cis-selective Pd catalyst for canola oil hydrogenation", Food Research International Journal, 2003, vol. 36, pp. 1069-1072.

[27] F.M. Bautista, J.M. Campelo, A. Garcia, R. Guardefio, D. Luna, and J.M. Marinas, "Influence of $\mathrm{Ni}-\mathrm{Cu}$ alloying on sepiolite-supported nickel catalysts in the liquid-phase selective hydrogenation of fatty acid ethyl esters", Journal of Molecular Catalysis A: Chemical, 1996, vol. 104, pp. 229-235.

[28] M. Stankovi'c, M. Gabrovska, J. Krsti'c, P. Tzvetkov, M. Shopska, T. Tsacheva,P. Bankovi'c, R.E. Kardjieva, andD.S. Jovanovi'c, "Effect of silver modification on structure and catalytic performance of $\mathrm{Ni}-\mathrm{Mg}$ /diatomite catalysts for edible oil hydrogenation", Journal of Molecular Catalysis A: Chemical, 2009, vol. 297, pp. 54-62.

[29] G.J. Yusem and P.N. Pintauro, "The electrocatalytic hydrogenation of soybean oil", Journal of American Oil Chemists Society, 1992, vol. 69 no. 5 , pp. 399-404.
[30] H.N. Basu, M.M. and Chakrabarty, "Studies on Conjugated Hydrogenation: Nickel Catalyst with Alcohols", Journal of American Oil Chemists Society, 1966, vol. 43, pp.119-121.

[31] B.K. Banik, K.J. Barakat, D.R. Wagle, M.S. Manhas, and A.K. Bose, "Microwave-Assisted Rapid and Simplified Hydrogenation", Journal of Organometallic Chemistry, 1999, vol. 64, pp. 5746-5753.

[32] B.L.P. Devi, M.S.L. Karuna, K.N. Rao, P.S. Saiprasad, and R.B.N Prasad "Microwave-assisted catalytic transfer-hydrogenation of safflower oil", Journal of American Oil Chemists Society, 2003, vol. 80 no. 10 , pp. 1003 - 1005.

[33] M.A. Tike and V.V. Mahajani, "Studies in catalytic transfer hydrogenation of soybean oil using ammonium formate as donor over 5\% Pd/C catalyst", Chemical Engineering Journal, 2006, vol. 123. pp. $31-41$.

[34] C.H. Maryott, "Process for reduction of unsaturated fatty acids and their esters", Paten A.S. no. US1097456, 1914

[35] E.R. Cousins, and R.O. Feuge, "Hydrogenation of methyl oleat in solvents", Journal of the American Oil Chemists Society,1960, vol. 37 , pp. $435-438$.

[36] S. Fokin, Journal of the Russian Physico-Chemical Society, 1908, vol. 40 , pp. $276-321$

[37] J.H. Sanders, "Partial hydrogenation of unsaturated glyceride oils in solvents", Paten A.S. no. US2520440, and Paten Inggris Raya no. GB642012, 1950.

[38] F. Hadiah, Irawati, T. Prakoso, Subagjo, T.H. Soearawidjaja, "Deacidification of Fatty Oils using Anion Exchange Resin", Proceedings of The 5 th Sriwijaya International Seminar on Energy and Environmental Science \& Technology, 2014, pp. 71-74.

[39] F. Hadiah, Irawati, T. Prakoso, Subagjo, T.H. Soearawidjaja, "Catalytic Transfer-Hydrogenation of Fatty Oil", Proceedings of The 5 th Sriwijaya International Seminar on Energy and Environmental Science \& Technology, 2014, pp. 75-79.

[40] Y.D. Li, C.W. Li, H.R. Wang, L.Q. Li, and Y.T. Qian, "Preparation of nickel ultra ${ }^{\circledR}$ ne powder and crystalline film by chemical control reduction", Mater Chem Phys., 1999, vol. 59, pp. 88-90.

[41] J.T. Richardson, B. Turk, M. Lei, K. Forster, andM.V. Twigg, "Effects of promoter oxides on the reduction of nickel oxide", Applied Catalysis A: General, 1992, vol. 83, pp. 87-101.

[42] F. Dorado, A. Lucas, P.B. Garcia, A. Romero, J.L. Valverde, andI. Ascencion, "SCR of NO by propene on monometallic (Co or $\mathrm{Ni}$ ) and bimetallic (Co/Ag or Ni/Ag) mordenite-based catalysts", Ind. Eng. Chem. Res., 2005, vol. 44, pp. 8988-8996.

[43] J.P. Fugassi, and G.A. Cowan, "Method of making silver formate", Paten A.S. no. US 2630 444, 1953.

[44] K. Fukuda, T. Onishi, and T. Tamaru, "Decomposition of formic acid on silver catalyst - Adsorption measurement during surface catalysis", Bulletin of the Chemical Society of Japan, 1969, vol. 42, no. 5, pp. $1192-1196$.

[45] H. Xiao, "Low Trans Fatty Acid Containing Hydrogenated Edible Oil",M. Sci. thesis, Miami University, Oxford, Ohio, 2007.

[46] A. Smidovnik, M. Naglic, and T. Koloini, "Kinetics of catalytic transfer hydrogenation of soybean oil", Journal of American Oil Chemists Society, 1994, vol. 7, no. 5, pp. 507-511.

[47] K. Mondal, and S.B. Lalvani, "A second-order model for catalytic transfer hydrogention of edible oils", Journal of American Oil Chemists Society, 2000, vol. 77, no. 1, pp. 1-8. 